DOE/ER/40150--137

DE91 000431

\title{
OPERATION OF THE RF CONTROLS IN THE CEBAF INJECTOR
}

\section{S. N. Simrock, J. A. Fugitt, J. C. Hovater \\ G. A. Krafft, C. K. Sinclair \\ Continuous Electron Beam Accelerator Facility \\ 12000 Jefferson Avenue \\ Newport News, VA 23606 \\ Continuous}

ELECTRON

BEAM

Accelerator

FACILITY

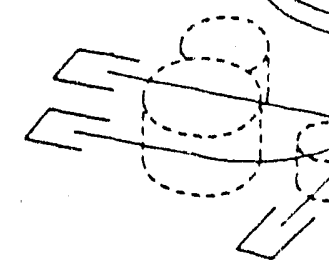

SURA SOUTHEASTERN UNIVERSITIES RESEARCH ASSOCIATION

\section{CEBAF}

Newport News, Virginia 
Copies available from:

\author{
Library \\ CEBAF \\ 12000 Jefferson Avenue \\ Newport News \\ Virginia 23606
}

The Southeastern Universities Research Association (SURA) operates the Continuous Electron Beam Accelerator Facility for the United States Department of Energy under contract DE-AC05-84ER40150.

\title{
DISCLAIMER
}

This report was prepared as an account of work sponsored by the United States government. Neither the United States nor the United States Department of Energy, nor any of their employees, makes any warranty, express or implied, or assumes any legal liability or responsibility for the accuracy, completeness, or usefulness of any information, apparatus, product, or process disclosed, or represents that its use would not infringe privately owned rights. Reference herein to sny specific commercial product, process, or service by trade name, mark, manufacturer, or otherwise, does not necessarily constitute or imply its endorsement, recommendation, or favoring by the United States government or any agency thereof. The views and opinions of authors expressed herein do not necessarily state or reflect those of the United States government or any agency thereof. 
Operation of the RF Controls

in the CEBAF Injector

\author{
S. N. Simrock, J. A. Fugitt, J. C. Bonter, G. A. Kraft, C. K. Sinclair \\ Continuous Electron Beam Accelerator Facility \\ 12000 Jefferson Avenue \\ Newport News, Virginia 23606
}

\begin{abstract}
The CEBAF injector bas produced its first relativintic beam with two ouperconducting cavities. Six RF control modules are used to control amplitude and phase in the chopper eavities, the buscher, the capture section, and the two superconducting cavities. In this paper the required stability and actual perfor. mance of the modules are discussed. For the superconducting carity control, performance is consistent with energr stability of $\approx 10^{-1}$.
\end{abstract}

\section{Introduction}

The main goal of the injector test underway is to produce chopped and bunched $\mathrm{CW}$ bean at $500 \mathrm{keV}$ and to eccelerate the beam to $5 \mathrm{Mel}$ with supercondueting carities. The test will rerify the design characteristics of the RF control srstem with bears and will lead to and design of the linac RF controls. At the end of this year the injector will be installed at its final location in the accelerator tumel.

\section{RF Control System}

Stringent RF control is needed at CEBAF under various operating conditions such as different field gradients and beam loads. A schematic diagram of the RF control system for the in. jector test is shown in Figure 1. Six control modules are used to control amplitude and phase in the two chopper resonators, the buncher, the capture section and tro standard superconducting carities.

One of the $33 \&$ RF control channels for the superconduct. ing carities, described elsewhere, ${ }^{1,2,3}$ is shown in Figure 2. The essential component is the standard RF control module which itself is divided into four separase sections. They wre a RF converter, is If board, an analog board and a digital section. The variable gain atages on the andog board allow optimization of the frequency reaponse in the feedback loops for phese and amplitude. A typical frequency response is shown in Figure 3 Variable frequency response is necessary to minimize residual errors ance the actual microphonic noise sources in the tunnel are not well known. The operator has control over the broad. bend guin from 20 to $60 \mathrm{~dB}$ and additional low frequeney gain up to $30 \mathrm{~dB}$. The rolloff frequency for the low frequency boost is adjustable from $1 \mathrm{Bz}$ to $200 \mathrm{Bz}$. Including the cavity, unity gain is reached at up to $100 \mathrm{kBz}$ rith a phase margin of 60 degrees Variations of the gain characteristics are also used to adjust for differences in the loaded $Q$ of the carities.

The RF drive to the chopper and buncher carities is pro. vided by $25 \mathrm{~W}$ class ' $\mathrm{C}$ ' amplifiers. The amplitude control sec. tion of the standard RF module required modification. The level modulator in the IF section is kept at a constant bias, providing sufficient drive for the $25 \mathrm{~W}$ emplifier. The amplified amplitude error signal feeds the input of a modulator which provides the DC power for the $25 \mathrm{~W}$ amplifier.

The bigh power amplifier for the capture section uses two 5 kW kystrons to provide $8.5 \mathrm{~kW}$ drive with some margin for am plitudi: control. Preamplifiers proride sufficient gais to operate the capture section with the drive of RF control module. Low pass filters with $100 \mathrm{Bz}$ rolloff bad to be added in the control loops to achieve the same overall frequency response as for the SC cavities.

The capture section needs to be temperature stabilized to $\pm 0.1^{\circ} \mathrm{F}$. A digital PID controller is implemented witbis the TACL system ${ }^{4}$. It uses the phase difference betreen drive and

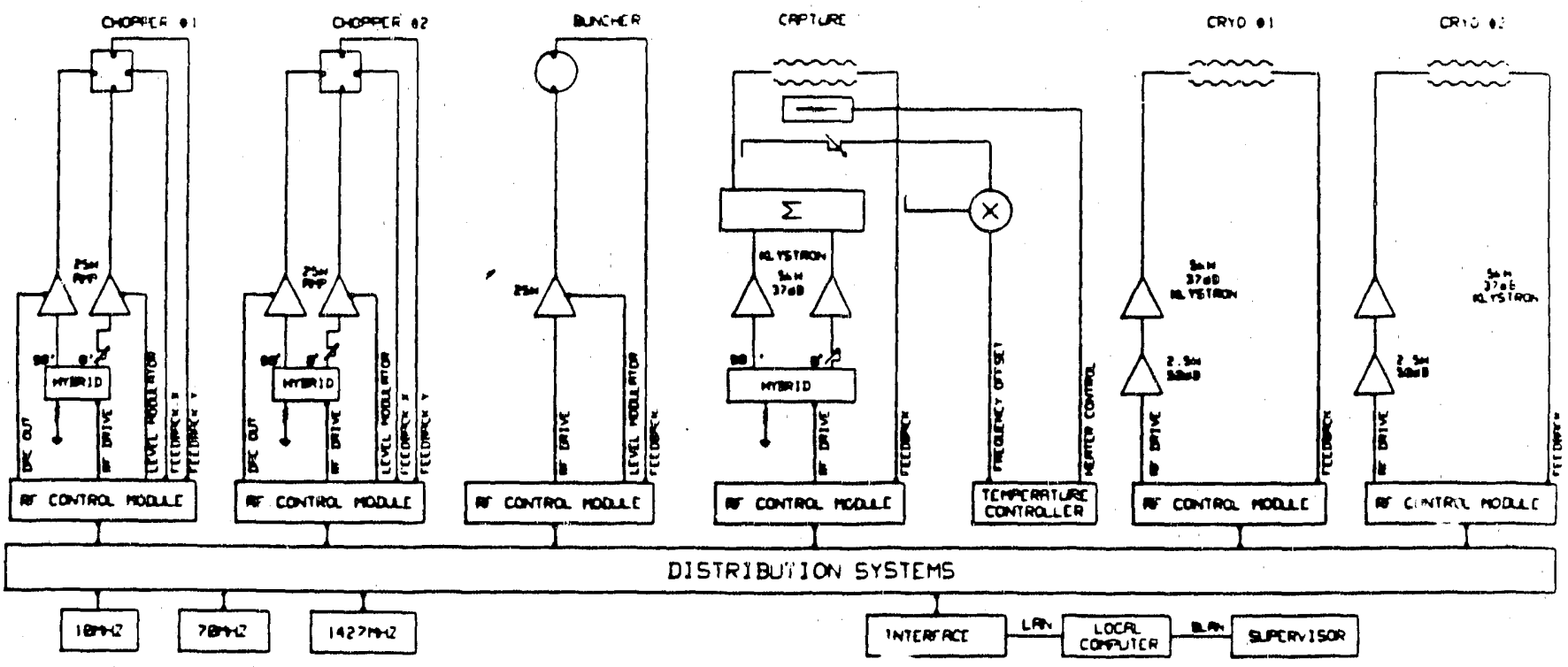

Figure 1. RF control oystem used in the injector test.

- Supported by U.S. Department of Energy. under contract DE.A C05.84ER40150.

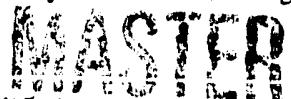

OISTRIBUTION OF THIS COCUMENT IS INALIMITED 
probe signals as a tempel siure error signal and a water servovalve serves as the coptrolles. In equilibrium, the beating porrer comes from the RF $(0.5 \mathrm{~kW})$. A $5 \mathrm{~kW}$ electrical beater provides the power for initial warmup.

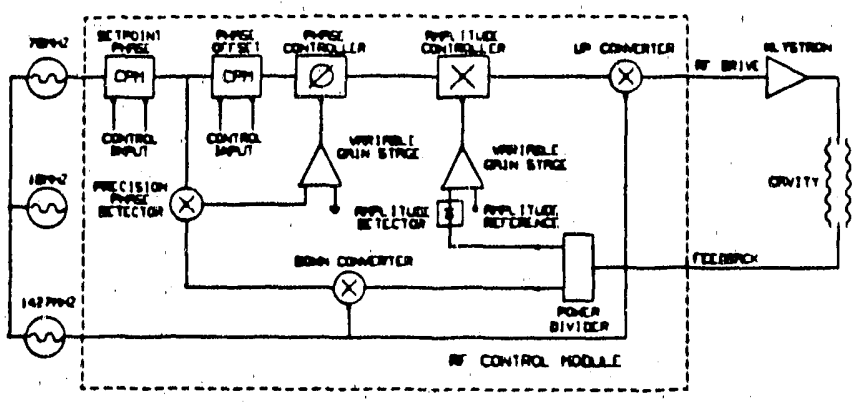

Figure 2. Simplified schematic of a standard CEBAF RF contral module.
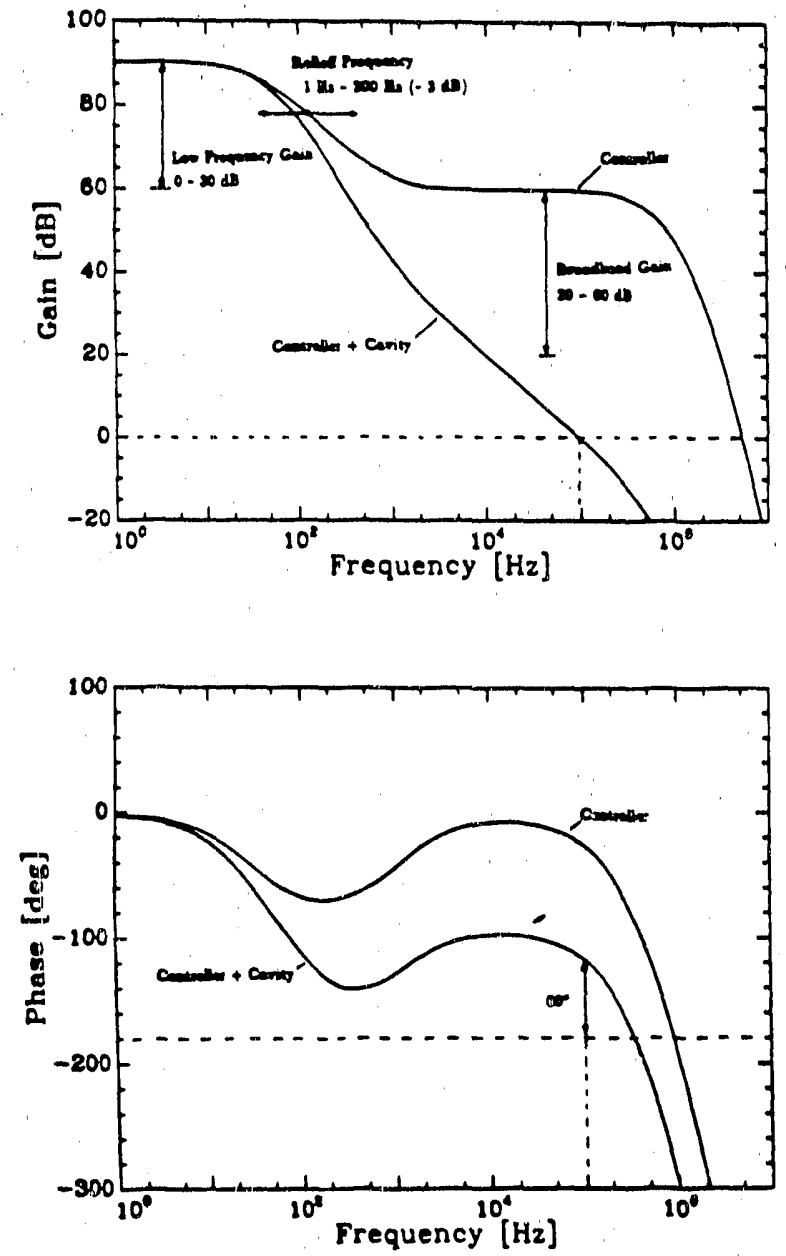

Figure 3. Frequency response (a) magnitude and (b) phase of gain atages in amplitude and phace controller. Broadband gain le variable from $20-60 \mathrm{~dB}$, low frequency gain from $0-30 \mathrm{~dB}$ and zallofi frequency from I Bt to $200 \mathrm{Bz}$.

\section{Performance of RF Control}

\section{Requirements}

The performence of the RF controls is measured by the residual amplitude and phee fluetuation in the cavities. Noise courcen are microphonic noire, beam induced noise (severe in pulsed mode operation) and system intrinvic noise sucb os noise from the muster oucillutor, from the low level amplifiers in the feedback loope, or from the klyatron. Table I nummerizes the re. quireconents for amplitude and phewe regulation to achiere $\Delta E / E$ of $10^{-1}$ in the find linac beam.

Trable 1

Error Talerances for the Fields in the Cerities

\begin{tabular}{|c|c|c|c|}
\hline Cavity & Amplitude Error & Phase Error $\left[^{\circ}\right]$ & \\
\hline \hline SC carity & $\pm 2 \times 10^{-1}$ & \pm 0.2 & correlated \\
SC carity & $\pm 4 \times 10^{-4}$ & \pm 0.5 & uncorrelated \\
Chopper & $\pm 1 \times 10^{-2}$ & \pm 0.2 & vertical \\
Chopper & $\pm 1 \times 10^{-2}$ & \pm 0.2 & horieontal \\
Buncher & $\pm 1 \times 10^{-2}$ & \pm 0.1 & \\
Capture & $\pm \$ \times 10^{-4}$ & \pm 0.2 & \\
\hline
\end{tabular}

\section{Superconducting Cavities}

The dominating noive sources in the unlocked (open loop) mode are phase and amplitude errors caused by mechanical vibrations of the carity. A typical phase error aignal for the two SC cavities is shown in Figure 4. The rignal bas peak to peak Auctuations of up to $20^{\circ}$, and the corresponding amplitude fluctuations are up to $6 \%$. The noise of two cavities in the same cryounit is not cornpletely correlated aince the mechanical resonarce frequencies are different and the excitation abows a broad band of frequencies up to a few hundred $\mathrm{Hz}$. In the locked case, noive reduction of $90 \mathrm{~dB}$ for frequencies below $100 \mathrm{Bz}$ wes achieved. For example, Figure 5 shows the amplitude noise spectrum for the regulated and unregulated case. The low frequency gain was set to $30 \mathrm{~dB}$, the rollofi frequency to $200 \mathrm{~Hz}$, and the broadband gain to $60 \mathrm{~dB}$. Below $1 \mathrm{kHz}$ the residual noise is dominated by $60 \mathrm{Bz}$, at the $\pm 7 \times 10^{-8}$ level. This level is three times greater than the correlated error limit. This noise will be reduced by aroiding ground loops, and its effects can be minimized by choosing different line phases for the control modules.

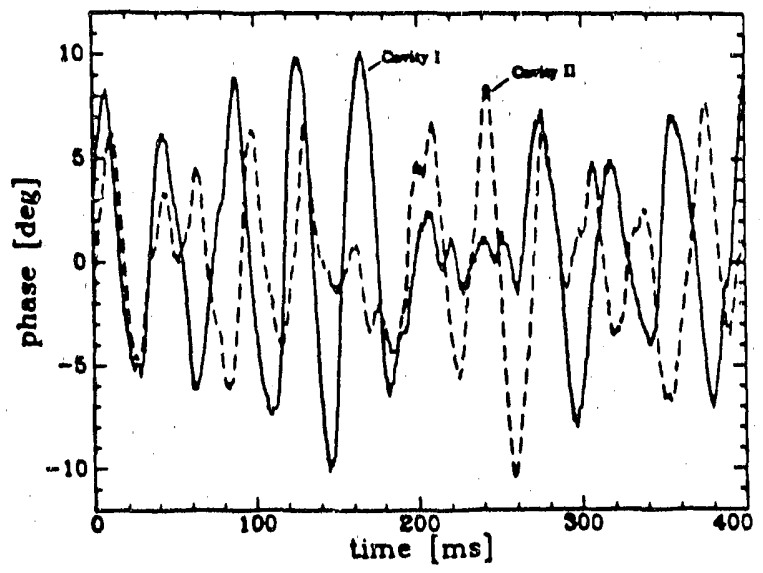

Figure 4. Phase noise in the two superconducting cavities of one eryounit. Data taken at ume time shows correlation of iganals. 


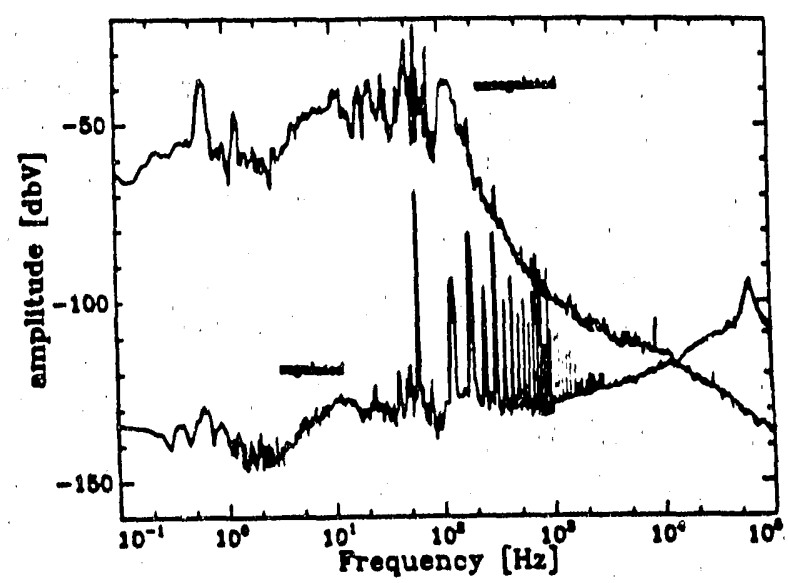

Figure 8. Spectrum of gredient fluctuations in regulated and noregulated roode.

Tuble 2 lists the amplitude and phase errors for the regulated carity without beam. The braadband noise for frequencies above $1 \mathrm{kHz}$ is about twice $n$ bigh 20 the aoise below $1 \mathrm{kHz}$. It should be noted that for the amplitude aciec measurements, in external amplitude detector was uned to detect the actual noise in the carity. This is necessary rince the amplitude detector in the feedbeck loop crentes 60 Hz noise which cannot be measured in the loop.

Table 2

Measured Erros for the Fields in the SC Cavities

\begin{tabular}{|c|c|c|}
\hline Bandwidth $[\mathrm{Hz}]$ & Amplitude Error & Phase Error $\left.0^{\circ}\right]$ \\
\hline $10^{0}$ & $\pm 1.1 \times 10^{-8}$ & $\pm 2.2 \times 10^{-3}$ \\
$10^{1}$ & $\pm 2.2 \times 10^{-8}$ & $\pm 2.3 \times 10^{-3}$ \\
$10^{2}$ & $\pm 6.9 \times 10^{-8}$ & $\pm 6.0 \times 10^{-3}$ \\
$10^{3}$ & $\pm 8.1 \times 10^{-8}$ & $\pm 8.1 \times 10^{-3}$ \\
$10^{4}$ & $\pm 1.1 \times 10^{-4}$ & $\pm 1.4 \times 10^{-2}$ \\
$10^{3}$ & $\pm 1.4 \times 10^{-4}$ & $\pm 3.2 \times 10^{-2}$ \\
$10^{\circ}$ & $\pm 1.5 \times 10^{-4}$ & \\
\hline
\end{tabular}

\section{Capture Section}

The phase and amplitude noise in the capture rection are. dominated by $720 \mathrm{~Hz}$ (and harmonics) from the klyatron power supply. Low frequency drifts are compensated with the temperature controller. To reduce the broudband noise in the capture cection to acceptable levels, the frequency reaponse of the coniral roodule will be modified.

Table 3

Mensured Errors for the Fields in the Capture Section

\begin{tabular}{|c|c|c|}
\hline Bandwidth [Bz] & Amplitude Error & Phase Error $\left[^{0}\right]$ \\
\hline $10^{2}$ & $\pm 2.2 \times 10^{-8}$ & $\pm 4.0 \times 10^{-3}$ \\
$10^{3}$ & $\pm 5.5 \times 10^{-8}$ & $\pm 3.6 \times 10^{-2}$ \\
$10^{4}$ & $\pm 3.3 \times 10^{-4}$ & $\pm 1.8 \times 10^{-1}$ \\
$10^{8}$ & $\pm 8.7 \times 10^{-4}$ & $\pm 2.2 \times 10^{-1}$ \\
$10^{4}$ & $\pm 9.5 \times 10^{-4}$ & $\pm 2.4 \times 10^{-1}$ \\
\hline
\end{tabular}

\section{Chopper and Buncher}

The phese and amplitude noise in the chopper and buncher reanatore are dominated by $60 \mathrm{~Hz}$ and brosdband noive from the amplitude detector and phwe reference. Slow frequency drifts are compensated with the temperature controller.
Thable 4

Measured Errors for the Fields in the Chopper Carities and the Buncher Carity

\begin{tabular}{|c|c|c|}
\hline Bandwidth [Bz] & Amplitude Error & Phese Error $\left.l^{0}\right]$ \\
\hline $10^{2}$ & $\pm 6.7 \times 10^{-8}$ & $\pm 6.5 \times 10^{-3}$ \\
$10^{3}$ & $\pm 1.1 \times 10^{-4}$ & $\pm 4.8 \times 10^{-2}$ \\
$10^{4}$ & $\pm 4.7 \times 10^{-4}$ & $\pm 0.5 \times 10^{-2}$ \\
$10^{8}$ & $\pm 1.4 \times 10^{-2}$ & $\pm 1.4 \times 10^{-1}$ \\
$10^{4}$ & $\pm 1.5 \times 10^{-2}$ & $\pm 1.0 \times 10^{-1}$ \\
\hline
\end{tabular}

\section{Conclusion}

The recent tests on the RF contral oystem at CEBAF have ahown that it is posible to contral phase in the SC cavities to $< \pm 0.2^{\circ}$ and the amplitude to $< \pm 4 \times 10^{-4}$. The microphonic noise in differeat cavities is unlikely to be correlated and it is corrected adequately. The correlated 00 Bs noise is $\pm 7 \times 10^{-8}$, greater then the error limit. This noise will be reduced by aroiding ground loops, and its effects can be minimized by different line pheses. The regulation of the field in the chopper and buncher curitiea is adequate. The amplitude contral for the capture rection is close to the requirements and the control module will be modified to reduce the noise to tolersble levels. Orerall, the RF controls for the CEBAF injector have been in operation for more than two months without failure.

\section{Acknowledgement}

The authors wish to express their thanks to $R$. Lauzé, K. Maboney, R. Atbott, G. Labti, M. Augustine, R. Vignaio, I. Ashtenari and R. Nelion who provided enormous belp for the successful test of the RF control oystem.

\section{References}

1. S. Simrock, C. Horater, S. Jones and J. Fugitt, Proceedings of the 1080 Particle Accelerator Conference, Chicago, Ilinois, March 20-23, 1889, p. 1885.

2. C. Bonter and J. Fugitt, 1988 Linear Accelerator Conference Proceedings, Newport Ners, Virgixia, October 3-7, 1988, p. 112.

3. I. Ashkenari and G. Labti, Proceedings of the 1989 Particle Accelerator Conference, Chicago, \#linois, March 20-23, 1989, p. 1861.

4. R. Bork, 1087 IEEE Particle Accelerator Corference, Washington, D.C., March 16-10, 1087, p. 523. 

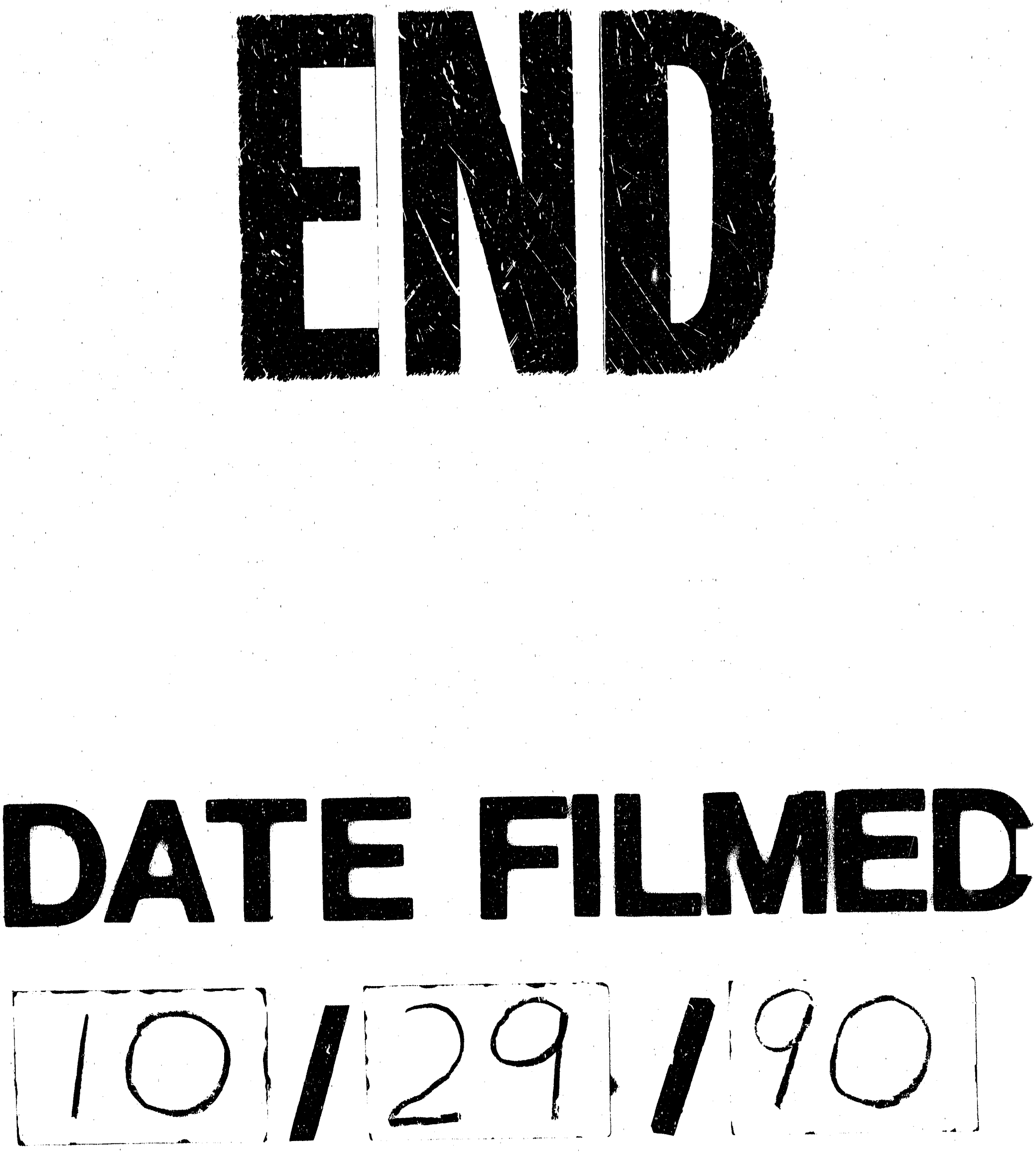
